Bond University

Research Repository

\title{
Investigating the relationship between social support and durable return to work
}

Watt, Bruce D.; Ford, Lucas; Doley, Rebekah M.; Ong, Sabrina; Hicks, Richard E.; Fritzon, Katarina; Cacciola, Tony

Published in:

Australasian Journal of Organisational Psychology

DOI:

10.1017/orp.2015.2

Licence:

Unspecified

Link to output in Bond University research repository.

Recommended citation(APA):

Watt, B. D., Ford, L., Doley, R. M., Ong, S., Hicks, R. E., Fritzon, K., \& Cacciola, T. (2015). Investigating the relationship between social support and durable return to work. Australasian Journal of Organisational Psychology, 8. https://doi.org/10.1017/orp.2015.2

\section{General rights}

Copyright and moral rights for the publications made accessible in the public portal are retained by the authors and/or other copyright owners and it is a condition of accessing publications that users recognise and abide by the legal requirements associated with these rights.

For more information, or if you believe that this document breaches copyright, please contact the Bond University research repository coordinator. 
Running head: SOCIAL SUPPORT AND DURABLE RTW

Investigating the Relationship between Social Support and Durable Return to Work

Watt, B. D., Ford, L. A., Doley, R. M., Ong, S., Hicks, R. E., Fritzon, K., \& Cacciola, T.

Correspondence to Bruce Watt, Faculty of Society and Design, Bond University, Gold Coast, QLD 4229 Australia, Ph 6175595 2653, Fax 61755952540 Email bwatt@bond.edu.au

Assistant Professor Dr Bruce Watt, Bond University, PhD, MPsych, BA (hons) Psych Lucas Ford, Bond University, MPsych, MSW, BSS (hons) Psych, BA Psych Anthr Associate Professor Dr Rebekah Doley, Bond University, BA(Hons), Grad Dip Psych Prac, MSc(Inv Psy), MPsych (Clin), PhD

Sabrina Ong, Bond University, MPsych, BA (hons) Psych

Professor Dr Richard Hicks, Bond University, BA(UNE), PG Cert. Ed(Lond), MA, D.Litt.et Phil(South Africa)

Associate Professor Dr Katarina Fritzon, Bond University, MSc (Surrey), PhD (Liverpool), MA Hons (Aberdeen)

Tony Cacciola, Wesfarmers, MBA

\section{Acknowledgement}

The authors would like to thank the Return to Work Assist and Data Management and Analytics personnel with Q-Comp for the assistance in establishing the research.

\section{Declaration of Interest}

The project was funded by Q-Comp, an independent statutory authority, established on 1 July 2003 under the Workers' Compensation and Rehabilitation Act 2003 to oversee Queensland's workers' compensation scheme.

This manuscript is an original work that has not been submitted to nor published anywhere else. All authors have read and approved the paper and have met the ICMJE criteria for authorship listed above 


\begin{abstract}
The aim of the current study was to investigate the relationship between social support and durable return to work (RTW) post-occupational injury. A total of 1179 questionnaires were posted to clients previously receiving vocational rehabilitation services from the Return to Work Assist program in Queensland, Australia. Participants were asked to indicate their current RTW status in addition to completing questionnaires measuring relationship with superior, relationships with colleagues, and social support external to the workplace. The statistical analysis included 110 participants. ANOVA indicated that participants in the RTW group reported significantly better relationships with their superiors and colleagues than participants in the non-durable RTW group. No significant differences were observed between the RTW, non-durable RTW, and no RTW groups on a measure of social support external to the workplace. Although the findings are limited by the low response rate, evaluation of demographics indicated the respondents were representative of the original target sample. The findings suggested that providing support in the workplace is an important area for intervention and may be a means of increasing durable RTW outcomes.
\end{abstract}

Keywords: durable return to work, social support, occupational injury, rehabilitation Word count: 6084 
Investigating the Relationship between Social Support and Durable Return to Work

The loss of work due to occupational injury can have a major impact on an individual's self-image, sense of personal worth, and social status (Szymanski \& Hershenson, 1998). Individuals who are absent from work for a prolonged period have a heightened risk of economic and social deprivation, and encounter significant barriers in returning to work (Dekkers-Sanchez, Wind, Sluiter, \& Frings-Dresen, 2010). In Australia, lost productivity and compensation claims amount to billions of dollars each year due to physical and psychological work-related injuries (Safework Australia, 2012; Zeiger et al., 2011). The total cost of workplace injury and illness in the 2000 to 2001 financial year was $\$ 34.3$ billion or the equivalent of 5\% of Australian Gross Domestic Product (GDP). The latest figures published by Safework Australia (2012) indicated that the total cost of workplace injury and illness remained at $4.8 \%$ of the GDP in the 2008 to 2009 financial year, though the total economic cost increased to approximately $\$ 60.6$ billion. An escalation in the number of people affected by work-related injuries and receiving disability benefits highlights the need to identify factors that facilitate and maintain return to work (RTW) post-occupational injury.

Much of the variability in RTW outcomes can be accounted for by what occurs in the workplace (Franche et al., 2005). Workplace factors may be more easily modified than medical factors. After the initial physical injury, psychosocial factors often contribute to the development and maintenance of disability (Waddell, 2006). Research has demonstrated the importance of support in the workplace in achieving positive RTW outcomes. Social support in the workplace may act to buffer stress and to promote organisational commitment (Gates, 2000). Conversely, perceived lack of support in the workplace has been linked to poor RTW outcomes. Injured workers reported support from supervisors and co-workers have been found to predict RTW outcomes and length of time to RTW post-occupational injury (Gates, 
1993; Feuerstein, Berkowitz, Haufler, \& Huang, 2001; Post, Krol, \& Groothoff, 2005; Young, 2010).

Post et al. (2005), however, found that employees reporting low supervisor support at their pre-injury workplace demonstrated a significantly higher RTW rate than employees reporting high supervisor support. Post and colleagues hypothesised that low supervisor support may result in increased pressure and motivation to attend work, thereby increasing the rate of RTW. Given this was hypothesised to be somewhat of a coercive motivational process, it would have been interesting to ascertain whether RTW for these participants was durable. Post et al. suggested that employees with more supportive supervisors, on the other hand, may feel more secure in their employment and comfortable in remaining out of work for a longer period of time.

The job demands-resources model (JD-R model; Demerouti, Bakker, Nachreiner, \& Schaufeli, 2001), an elaboration of the job demand-control model (Karasek, 1979), may explain the importance of social support in the workplace. The JD-R model classifies psychosocial risk factors into two general categories: job demands (JD) and job resources (JR). The model describes a health impairment process whereby high JD, such as high workload and physical, psychological, or organisational pressures, exhaust employees’ physical and mental resources, leading to health problems and injury (Demerouti et al., 2001). The model also describes a motivational process whereby JR, such as autonomy and colleague and supervisor support, have the potential to increase employees' motivation, growth, and development (Demerouti et al., 2001).

The JD-R model has been empirically supported with high JD related to burnout and the development of workplace related health problems and JR related to increased motivation and work engagement (Bakker, Demerouti, De Boer, \& Schaufeli, 2003a). JR, such as 
colleague and supervisor support, have been found to buffer the impact of JD (Bakker, Demerouti, Taris, Schaufeli, \& Schreurs, 2003b) and to maintain work engagement under conditions of high JD (Bakker, van Veldhoven, \& Xanthopoulou, 2010). These findings suggest that organisations can impact the health and well-being, and perhaps RTW status, of their employees by managing and altering organisational levels of JD and JR.

More generally, research has demonstrated that individuals without supportive relationships, whether professional or personal, experience greater stress than those with supportive relationships. Having people available for support and assistance can enhance coping and provide a buffer against stress (Baumeister \& Leary, 1995). Baumeister and Leary postulated that relationships and social interactions are fundamental to human beings, that people strive for belongingness, and that people have an innate drive to form and maintain social relationships.

The importance of social relationships can be seen in Baumeister's (1991) model of a meaningful life, which states that human experience is shaped by four factors of meaning: purpose, efficacy, value, and self-worth. Baumeister argued that the perception of a meaningful life depended upon satisfying these four factors. Stillman et al. (2009) examined how social exclusion impacted upon the four factors in Baumeister's model. Stillman et al. found that social exclusion significantly reduced participants' reported sense of purpose, efficacy, value, and self-worth. Based on these findings, Stillman et al. concluded that social exclusion, by decreasing a sense of meaningfulness, is likely to decrease goal-oriented behaviours, fulfilment seeking, motivation, and sense of control over life. In applying these findings to the RTW context, it is possible that injured workers experiencing social support and a sense of belongingness in the workplace feel a greater sense of meaningfulness in their lives. With this additional meaning and purpose, injured workers may be more focused on future goals than on immediate needs, therefore increasing their capacity to withstand the 
pain and discomfort often associated with the RTW process. With increased social support and a greater sense of meaning, injured workers may feel more motivated to maintain RTW during difficult periods and more in control of their environment.

Increasingly the pivotal role of psychosocial factors in the RTW process has been acknowledged in the RTW literature (Burton, Kendall, Pearce, Birrell, \& Bainbridge, 2008; Shaw, Pransky, Patterson, \& Winters, 2005). This perspective is reflected in the disability paradigm, which postulates that the causes of disability encompass more than the original injury/disease producing event (Loisel \& Durand, 2008). As a result, RTW does not depend on resolution of the condition but rather on diverse psychosocial and occupational factors which contribute to the disability. Work disability must therefore be seen as different from the original disorder having initiated the disability (Loisel et al., 2001). The perspective, that RTW may be hindered by a range of factors, is also reflected in the flags model (Kendall, Linton, \& Main, 1997; Main, Sullivan, \& Watson, 2008). The flags system was initially developed by Kendall and colleagues (1997) and further elaborated by Main et al. (2008) as a means of identifying and managing psychosocial factors in low back pain. In this system, flags are viewed as obstacles that impede recovery and prolong the likelihood of disability (Main et al., 2008). For instance, orange flags are psychological in nature and include clinical depression and anxiety, while yellow flags are psychosocial and include beliefs and expectations about RTW and unhelpful coping strategies. Recognising the important role of workplace relationships, blue flags in this model include occupational factors, such as support from colleagues and management. Reflecting the importance of psychosocial and workplace factors for successful RTW, interventions such as the Sherbrooke Model and Therapeutic Return to Work, which focus on both clinical and occupational factors have demonstrated effectiveness in improving RTW outcomes (Durand \& Loisel, 2001; Loisel et al., 1997). 
A return to the workplace does not always indicate the end of injury or the RTW process. Research has found that the majority of workers with upper extremity and lower back injuries reported the ongoing impact of the injury on work and activities of daily living one year post-injury (Pransky et al., 2000). Consistent with the JD-R model, lack of support in the workplace may decrease the motivation of injured workers to persist during times of hardship, leading to poor RTW outcomes (Karasek, Triantis, \& Chandhry, 1982). In Australia, a durable RTW outcome has been defined as an injured worker maintaining work post-occupational injury for at least six months (Murphy \& Jackson, 2013). Minimal research, however, has explored the factors contributing to durable RTW outcomes (Young, 2010).

In a prospective study, Young (2010) analysed whether a range of demographic, occupational, and injury-related variables were able to differentiate between workers who maintained work post-injury from those who did not. Of the variables explored, Young found that only self-reported relationship with one's supervisor was significantly related to employment status, with poor supervisor relationships associated with non-durable RTW outcomes. Similarly, in a qualitative study $(n=30)$, the most commonly provided reasons for non-durable RTW outcome, cited by half of the participants, pertained to the detrimental attitudes and behaviours of co-workers and supervisors (Murphy \& Jackson, 2013). The current study further explored this relationship between support in the workplace and durable RTW outcome.

Although the importance of social support in the workplace has been demonstrated, less is known about the relationship between social support external to the workplace and RTW outcome, such as support from family and friends. In a sample of 926 occupationally injured workers with periods of absence ranging from six to twelve weeks, Brouwer and colleagues $(2009,2010)$ found that perceived social support was significantly related to 
length of absence from work. Workers who reported higher levels of social support returned to work earlier compared to workers with less social support. However, this relationship was found for workers with physical conditions but not mental conditions, indicating that the importance of social support may differ according to injury. Brouwer et al. (2010) utilised a self-constructed measure of social support with unknown psychometric qualities. The current study extended this research by using a well validated measure of social support to further explore the relationship between social support external to the workplace and RTW outcome.

Based on previous research, it was hypothesised that participants with durable RTW outcomes, compared to participants with non-durable RTW outcomes, would report higher levels of support in the workplace, from both superior and colleagues. It was also hypothesised that participants with durable RTW outcomes would report higher levels of social support outside of the workplace than participants with non-durable RTW and no RTW (NRTW) outcomes.

\section{Methodology}

\section{Study Location and Participants}

Participants were previous clients of the Return to Work Assist (RTWA) program operated by Q-Comp, an independent statutory authority established under the Workers' Compensation and Rehabilitation Act 2003 in Queensland, Australia. Q-Comp established RTWA to provide individualised support to workers with injuries which preclude them from returning to their previous employment. Injured workers can access RTWA services after their worker's compensation claim has ceased. Given these circumstances, clients of RTWA have often experienced long-term unemployment following their workplace injury and multiple barriers to successful RTW. RTWA is a voluntary service also working with clients seeking compensation from their employers due to workplace injury. Under Section 267 of 
the Workers' Compensation and Rehabilitation Act 2003, injured workers with an open claim for compensation against their employer have been mandated to satisfactorily participate in the RTWA program to mitigate their loss.

RTWA utilises a two-pronged approach to help clients RTW after sustaining workrelated injuries. The first is to prepare clients for re-employment through activities such as resume writing, job search, and interview training. Secondly, the program adopted a career development approach to harness the potential of clients for prospective career changes, as well as career advancement.

The current study was conducted in the context of an independent evaluation of RTWA program by the authors. A total of 1179 previous RTWA clients were randomly selected from the Q-Comp database to be included in this component of the evaluation. Potential participants were involved with RTWA for various amounts of time from 2008 2012. Potential participants were contacted via post and provided with information regarding the evaluation. One hundred and forty-three (12.1\%) letters were returned as the participants no longer resided at the postal address. In total, 113 (10.9\%) surveys were received, either completed or partially completed.

\section{Procedure and Measures}

Prior to commencing this component of the evaluation, ethics approval was obtained from the authors' university research and ethics committee. Introductory letters, detailing the nature of the evaluation, were posted to the randomly selected participants two weeks prior to posting the questionnaire booklet. A questionnaire booklet, along with an explanatory statement, was then posted to the participants. The questionnaires included in the booklet were intended to capture a range of information from the clients, including demographic information, information regarding the RTW process, mental and physical health, consumer 
satisfaction, and social support. Participants were asked to complete and return the questionnaires in a provided reply paid envelope. Former RTWA clients were informed in the explanatory statement that participation was voluntary and that they would not be penalised if the questionnaires were not returned. Follow-up letters requesting completion of the questionnaires were posted three weeks later.

Of relevance to the current study, participants completed the Questionnaire on the Experience and Evaluation of Work (QEEW; van Veldhoven, Meijman, Broersen, \& Fortuin, 2002) and the Multidimensional Scale of Perceived Social Support (MSPSS; Zimet, Dahlem, Zimet, \& Farley, 1988). The QEEW (van Veldhoven et al., 2002) is a measure that is widely used in the Dutch vocational health care services and in research (Bekker, Nijssen, \& Hens, 2001; Hubert \& van Veldhoven, 2001). Two subscales of the QEEW, the relationships with colleagues subscale and the relationship with superior subscale, were included in the battery of questionnaires. Participants are asked to indicate how frequently statements apply to them on a four point rating scale; always, often, sometimes, never. Items are the same on both subscales, with reference to either colleagues or superior, for example "Can you count on your colleagues/superior when you encounter difficulties in your work?” "Do you have conflicts with your colleagues/superior?” Both subscales were transformed to a $0-100$ range as indicated in the QEEW manual.

Although the Dutch version of this instrument has been well validated in the European context, limited research has been conducted on the English version of the QEEW. The Dutch version of the QEEW has demonstrated acceptable internal consistency for all scales ( $\alpha>$.74; Cortina, 1993). In particular, the relationship with superior subscale $(\alpha=.88)$ and the relationships with colleagues subscale $(\alpha=.82)$ have demonstrated good internal consistency (van Veldhoven, Taris, de Jonge, \& Broersen, 2005). In the current study, Cronbach’s alpha for the relationship with superior and relationships with colleagues 
subscales was .94 and .87, respectively. The factor structure of the QEEW has been supported with confirmatory factor analysis (van Veldhoven et al., 2002).

The Multidimensional Scale of Perceived Social Support (MSPSS; Zimet et al., 1988) is a 12-item measure that assesses the level of perceived support from family, friends, and a significant other (Zimet et al., 1988). Participants are asked to indicate their agreement with each statement on a seven point scale, ranging from very strongly disagree to very strongly agree. Examples of items include: "My family really tries to help me”, “I can count on my friends when things go wrong”, and “There is a special person in my life who cares about my feelings.” In the current study, only the total score was utilised as an overall measure of social support. Reliability and validity has been established across multiple samples (Cecil, Stanley, Carrion, \& Swann, 1995; Zimet, Powell, Farley, Werkman, \& Berkoff, 1990). The MSPSS has demonstrated high internal consistency, ranging from .84 to .92 for the total scale (Cecil et al., 1995; Zimet et al., 1990). Cronbach’s alpha in the current study was .86.

Concurrent validity of the MSPSS was supported with significant correlations with the Social Support Behaviours Scale (SS-B; Kazarian \& McCabe, 1991).

\section{Results}

Of the 1179 surveys that were posted to potential participants, 113 were returned. Three surveys were excluded from the analysis as these participants reported zero contacts with RTWA. In total 110 surveys were included in the analyses. Some surveys were only partially completed; the number of participants who completed each section is indicated below.

\section{Descriptives}

The sample was evenly split with 43 males and females, and 24 participants not specifying gender. The average age of participants at time of injury was 46.40 years $(S D=$ 
11.06) with ages ranging from 21 to 66 years. Participants were asked to report their injury. Utilising the categories from Queensland's Workers' Compensation and Rehabilitation Act 2003, these injuries $(n=98)$ were classified as indicated in Table 1.

Insert Table 1 about here.

Of the 105 returned surveys where participants reported RTW status, 49.5\% reported current employment or previous return to employment of greater than 12 months (durable RTW; $n=52$ ), 25.7\% reported previous return to work of less than 12 months but no current employment (non-durable RTW; $n=27$ ), and $24.8 \%$ reported no return to work $(n=26)$. Of those in the durable RTW group, the average length of RTW was 15.23 months $(S D=10.60)$. These values ranged from 2 months to 60 months. For non-durable RTW participants, the average length of non-durable RTW was 3.56 months $(S D=3.30)$, ranging from less than a month to 11 months.

Due to the low response rate and concerns regarding the generalisability of the findings, demographic data for the current sample was compared to a separate database of 1836 RTWA clients. Compared to the RTWA database, the current sample was more evenly distributed in terms of gender, with the database including $71 \%$ males, compared to $43 \%$ in the current sample. However, a high proportion of respondents in the current sample did not indicate their gender. In terms of age, the samples were comparable with the current sample approximately five years older; $M=46.40$ in the current sample; $M=41.91$ in the RTWA database. Although the database did not indicate whether RTW was durable, similar rates of RTW were observed in both samples; $75 \%$ in the current sample and $76 \%$ in the database. The types of injuries in the samples were also comparable, with lower rates of musculoskeletal injuries and higher rates of multiple injuries in the current sample: upper extremity $26.4 \%$ vs $29.4 \%$, lower extremity $18.2 \%$ vs $16.1 \%$, musculoskeletal $23.6 \%$ vs 
$34.7 \%$, psychiatric $6.4 \%$ vs $9.1 \%$, and multiple injuries $14.5 \%$ vs $9.5 \%$. Based on these comparisons, with the exception of gender, the current sample appeared similar to that of the larger RTWA population.

\section{Relationships with Superior and Colleagues}

A multivariate analysis of variance (MANOVA) was utilised to ascertain whether the durable RTW $(n=44)$ and non-durable RTW $(n=15)$ groups reported significant differences in the quality of their relationships with their superiors and colleagues. Means and standard deviations are displayed in Table 2. Using Pillai’s Trace, the between group difference for the combined superior and colleague variables was statistically significant, $V=0.14, F(2,53)$ $=4.34, p=.018, \eta^{2}=.71$. Separate univariate ANOVAs revealed statistically significant effects for both colleague support, $F(1,54)=4.08, p=.048, \eta^{2}=.07$, and support from superior, $F(1,54)=8.83, p=.004, \eta^{2}=.14$. Participants who sustained RTW were significantly more likely to report positive support from colleagues and supervisor, compared to non-durable RTW participants.

Insert Table 2 about here.

\section{Social Support Outside of the Workplace}

An ANOVA was utilised to ascertain whether social support differed according to injury as was found in previous research, however, no significant differences were found, $F$ $(4,88)=1.45, p=.225, \eta^{2}=.06$. An ANOVA was also utilised to ascertain whether there were significant differences in reported social support between the durable RTW, nondurable RTW, and NRTW groups. No significant differences were found between the groups, $F(2,97)=.09, p=.917, \eta^{2}=.002$, indicating that the RTW, non-durable RTW, and NRTW groups reported similar levels of social support. These findings are displayed in Table 3. 
Insert Table 3 about here.

\section{Discussion}

This study examined the influence of social support, both in and out of the workplace, on RTW outcomes. Previous research has indicated that social support in the workplace is an important factor in facilitating and maintaining return to work post-occupational injury (Feuerstein et al., 2001; Young, 2010). The current study found that participants with durable RTW outcomes reported significantly better relationships with their superiors and colleagues than participants with non-durable RTW outcomes. These findings appear consistent with the JR-D model (Demerouti et al., 2001) and the findings of Bakker et al. (2003a, 2003b). Returning to work after injury is likely a challenging and stressful endeavour for the injured worker. Perhaps JR in the form of colleague and supervisor support served to buffer the challenges associated with maintaining RTW. Colleague and supervisor support may have provided the injured worker with increased motivation to maintain RTW, despite pain and discomfort. The findings of the current study also appear in line with Baumeister's model of meaningful life (1991). Perhaps injured workers experiencing social support and a sense of belongingness in the workplace felt a greater sense of meaningfulness in their lives, enabling them to remain focused on future goals and increasing their capacity to withstand the pain and discomfort associated with RTW. With the support of colleagues and supervisor, injured workers may have felt more in control of their work environment and able to seek assistance or accommodations as needed.

The findings of the current support the use of RTW interventions that include a focus on occupational factors, such as the Sherbrooke Model or Therapeutic Return to Work (Durand \& Loisel, 2001; Loisel et al., 1997). The RTW process could be facilitated by a vocational rehabilitation case manager, or RTW coordinator, assessing the nature of 
workplace relationships and mediating conflict as appropriate. Although creating an initial increase in workload, such an intervention is likely to result in a more durable RTW outcome, thereby minimising the need to re-commence the RTW process at a later date.

Returning to work post-occupational injury is a complex process, involving financial and physical stressors. Individuals returning to work are likely to face barriers and limitations to employment and daily living not previously encountered. A supportive workplace environment is likely to increase an individual's willingness to persist through these difficult times, an outcome beneficial for the individual and the employer. Supportive relationships in the workplace are likely indicative of a flexible, understanding, and accommodating approach to the RTW process.

Increasing the provision of support in the workplace post-occupational injury can be facilitated by increasing the awareness of management and improving their ability to manage this process. For instance McLellan, Pransky, and Shaw (2001) developed a disability management training program for supervisors. The goal of this training was to take a supportive approach to workers with work-related injury, to facilitate communication, to encourage the reporting of injury among workers, and to implement accommodations when possible. The brief training (1.5 hours) significantly improved supervisor confidence in managing work related injury concerns. Many supervisors also reported decreases in lost work time within their departments. Communication factors, enquiring about the worker's well-being, were identified as most important in reducing worker disability. Communication and assertiveness training may also be beneficial for workers engaging in the RTW process as a means of ensuring that their workplace and injury-related needs are met.

Previous research has indicated that social support external to the workplace, support from family and friends, is an important factor in the RTW process (Brouwer, 2009). The 
results of the present study indicated that social support external to the workplace did not differ between the durable RTW, non-durable RTW, and no RTW groups. These findings may be attributed to the sample utilised in the study. Many of the participants in the sample had experienced long-term unemployment due to occupational injury, negatively impacted by a range of adverse physical, emotional, and social factors. It may also be anxiety provoking and distressing for family members and friends to see the person they care about in pain. Family and friends may lack an understanding of the RTW process and be unaware that RTW can actually aid recovery. Consequently, family members or friends may empathise with the injured worker and encourage him or her to delay their RTW until symptom improvement or resolution. External social support may encourage some injured workers to RTW, for others the same support may encourage non RTW. Future research could explore mechanisms by which family and friends may or may not contribute to the RTW process.

For the participants with a non-durable RTW outcome, the average length of time at work prior to cessation was approximately five months. This suggests that the vocational rehabilitation post-RTW may be beneficial in maintaining employment. While this may not be possible for many services due to workload pressures, RTWA implemented a strategy whereby text messages were sent to previous clients after pre-determined lengths of time to follow-up on RTW status and to offer a recommencement of services, if required. Such an intervention may be an effective means of managing heavy vocational rehabilitation workloads, the need for client independence, and the ongoing provision of support for clients in RTW efforts.

A limitation of the current study was the low response rate. While 1179 questionnaires were posted to participants, only 113 (10.9\%) were returned. The low response rate may have resulted in a sampling bias, decreasing the representativeness of the sample. For instance, due to time pressures, potential participants who were employed may 
have been less likely to complete the battery of questionnaires. However, this does not appear to be the case as the current sample's RTW rate was comparable to that of a larger RTWA sample. That stated, given the long-term unemployment due to occupational injury experienced by the majority of the sample, the generalisability of the results may be limited. Future research may wish to explore specific supervisor and co-worker behaviours and attitudes that assist in facilitating and maintaining an individual in the workplace post-injury. With scant studies considering the determinants of RTW for the long-term unemployed due to injury (Post et al., 2005), additional research is required to determine effective RTW practices with this complex client group. In interpreting the current study findings it should also be considered that, while the average length of RTW for the durable RTW group was approximately 15 months, some of the participants in this group may still stop working.

The current study was a correlational research design, limiting inferences that can be drawn regarding causality. Workplace relationships may contribute to the durability of RTW. Conversely, durability of RTW may shape retrospective accounts of workplace relationships, insofar as inability to sustain RTW may lead to negative appraisal of the former workplace. Future research employing a prospective design is necessary to appraise potential causal associations.

The findings from the current study contribute to the literature that social support in the workplace is a crucial component to the RTW process in both the facilitation and maintenance of positive RTW outcomes. Interventions aimed at improving support and relationships in the workplace are likely to result in beneficial outcomes for both the injured worker and the employer. 


\section{References}

Bakker, A., Demerouti, E., De Boer, E., \& Schaufeli, W. (2003a). Job demands and job resources as predictors of absence duration and frequency. Journal of Vocational Behavior, 62, 341-356. http://dx.doi.org/10.1016/S0001-8791(02)00030-1

Bakker, A. Demerouti, E., Taris, T., Schaufeli, W., \& Schreurs, P. (2003b). A multi-group analysis of the job demands-resources model. European Journal of Work and Organizational Psychology, 12, 393-417.

Bakker, A., van Veldhoven, M., Xanthopoulou, D. (2010). Beyond the demand-control model: Thriving on high job demands and resources. Journal of Personnel Psychology, 9, 3-16. http://dx.doi.org/10.1027/1866-5888/a000006

Baumeister, R. (1991). Meanings of life. New York: Guilford Press.

Baumeister, R. \& Leary, M. (1995). The need to belong: Desire for interpersonal attachments as a fundamental human motivation. Psychological Bulletin, 117, 497-529. http://dx.doi.org/10.1037/0033-2909.117.3.497

Bekker, M., Nijssen, A., \& Hens, G. (2001). Stress prevention training: Sex differences in types of stressors, coping, and training effects. Stress and Health, 17, 207-218. doi: 10.1002/smi.900

Brouwer, S., Krol, B., Reneman, M., Bultmann, U., Franche, R., van der Klink, J., \& Groothoff, J. (2009). Behavioral determinants as predictors of return to work after long-term sickness absence: An application of the theory of planned behavior. Journal of Occupational Rehabilitation, 19,166-174. doi: 10.1007/s10926-009-9172-5

Brouwer, S., Reneman, M., Bultmann, U., van der Klink, J., \& Groothoff, J. (2010). A 
prospective study of return to work across health conditions: Perceived work attitude, self-efficacy and perceived social support. Journal of Occupational Rehabilitation, 20, 104-112. doi:10.1007/s10926-009-9214-z

Burton, A., Kendall, N., Pearce, B., Birrell, L., \& Bainbridge, L. (2008). Management of upper limb disorders and the biopsychosocial model. London: HSE Books.

Cecil, H., Stanley, M., Carrion, P., \& Swann, A. (1995). Psychometric properties of the MSPSS and NOS in psychiatric outpatients. Journal of Clinical Psychology, 51, 593602. doi: 10.1002/1097-4679(199509)51:5<593::AID-JCLP2270510503>3.0.CO;2-W

Cohen, J. (1988). Statistical power analysis for the behavioral sciences ( $2^{\text {nd }}$ ed.). New Jersey: Lawrence Erlbaum.

Cortina, J. (1993). What is coefficient alpha? An examination of theory and applications. Journal of Applied Psychology, 78, 98-104. doi: 10.1037/0021-9010.78.1.98

Dekkers-Sanchez, P., Wind, H., Sluiter, J., \& Frings-Dresen, M. (2010). Qualitative study of perpetuating factors for long term sick leave and promoting factors for return to work: Chronic work disabled patients in their own words. Journal of Rehabilitation Medicine, 42, 544-552. doi: 10.2340/16501977-0544

Demerouti, E., Bakker, A., Nachreiner, F., \& Schaufeli, W. (2001). The job demandsresources model of burnout. Journal of Applied Psychology, 86, 499-512. http://dx.doi.org/10.1037/0021-9010.86.3.499

Durand M. \& Loisel P. (2001). Therapeutic return to work: Rehabilitation in the workplace. Work : A Journal of Prevention, Assessment \& Rehabilitation, 17, 57-63. Retrieved from http://www.iospress.nl/journal/work/ 
Feuerstein, M., Berkowitz, S., Haufler, A., Lopez, M., \& Huang, G. (2001). Working with low back pain: Workplace and individual psychosocial determinants of limited duty and lost time. American Journal of Industrial Medicine, 40, 627-638. doi: 10.1002/ajim.10000

Franche, R., Cullen, K., Clarke, J., Irvin, E., Sinclair, S., \& Frank, J., The Institute for Work \& Health Workplace-Based RTW Intervention Literature Review Research Team. (2005). Workplace-based interventions: a systematic review of the quantitative literature. Journal of Occupational Rehabilitation, 12, 233-256. doi:10.1007/s10926005-8038-8

Gates, L. (1993). The role of the supervisor in successful adjustment to work with a disabling Condition: Issues for disability policy and practice. Journal of Occupational Rehabilitation, 3, 179-190. doi: 10.1007/BF01097428

Gates, L. (2000). Workplace accommodation as a social process. Journal of Occupational Rehabilitation, 10, 85-98. doi: 10.1023/A:1009445929841

Hubert, A., \& van Veldhoven, M. (2001). Risk sectors for undesirable behaviour and mobbing. European Journal of Work and Organizational Psychology, 10, 415-424. doi: 10.1080/13594320143000799

Karasek, R. (1979). Job demands, job decision latitude, and mental strain: Implications for job redesign. Administrative Science Quarterly, 24, 285-305. http://dx.doi.org/10.2307/2392498

Karasek, R., Triantis, K., \& Chaudhry, S. (1982). Coworker and supervisor support as 
Moderators of associations between task characteristics and mental strain. Journal of Organizational Behavior, 3, 181-200. doi: 10.1002/job.4030030205

Kazarian, S., \& McCabe, S. (1991). Dimensions of social support in the MSPSS:

Factorial structure, reliability, and theoretical implications. Journal of Community Psychology, 19, 150-160. doi: 10.1002/1520-6629(199104)19:2<150::AIDJCOP2290190206>3.0.CO;2-J

Kendall, N., Linton, S., \& Main, C. (1997). Guide to assessing psychosocial yellow flags in acute low back pain: Risk factors for long-term disability and work loss. Wellington, New Zealand: Accident Rehabilitation \& Compensation Insurance Corporation of New Zealand and the National Health Committee, Ministry of Health.

Loisel, P., \& Durand M. (2008). Working with the employer: The Sherbrooke Model. In I. Shultz \& R. Gatchel (Eds.), Handbook of complex occupational disability claims: Early risk identification, intervention, and prevention (pp. 479-488). New York: Springer.

Loisel, P., Durand, M., Berthelette, D., Vezina, N., Baril, R., Gagnon, D.,...Tremblay, C. (2001). Disability prevention: New paradigm for the management of occupational back pain. Disease Management and Health Outcomes, 9, 351-360. doi: $10.2165 / 00115677-200109070-00001$

Loisel, P., Abenhaim, L., Durand, P., Esdaile, J., Suissa, S., Gosselin, L.,...Lemaire, J. (1997). A population-based, randomized clinical trial on back pain management. Spine, 22, 2911-2918. doi: 10.1097/00007632-199712150-00014

Main, C., Sullivan, M., \& Watson, P. (2008). Pain Management: Practical applications of 
the biopsychosocial perspective in clinical and occupational settings. Edinburgh: Churchill Livingstone.

McLellan, R., Pransky, G., \& Shaw, W. (2001). Disability management training for supervisors: A pilot intervention program. Journal of Occupational Rehabilitation, 11, 33-40. doi: 10.1023/A:1016652124410

Murphy, G. \& Jackson, M. (2013). Barriers to sustained return-to-work reported by those returning to work post traumatic spinal cord injury rehabilitation. The Open Rehabilitation Journal, 6, 21-25. Retried from http://benthamscience.com/open/torehj/articles/V006/21TOREHJ.pdf

Post, M., Krol, B., \& Groothoff, J. W. (2005). Work-related determinants of return to work of employees on long-term sickness absence. Disability and Rehabilitation, 27, 481488. doi:10.1080/09638280400018601

Pransky, G., Benjamin, K., Hill-Fotougi, C., Himmelstein, J., Fletcher, K., Katz, J., \& Johnson, W. (2000). Outcomes in work-related upper extremity and low back injuries: Results of a retrospective study. American Journal of Industrial Medicine, 37, 400409. doi: 10.1002/(SICI)1097-0274(200004)37:4<400::AID-AJIM10>3.0.CO;2-C

Safework Australia (2012). Australian work health and safety strategy 2012-2022. Canberra: Author. Retrieved from http://www.safeworkaustralia.gov.au/sites/SWA/about/Publications/Documents/719/ Australian-WHS-Strategy-2012-2022.pdf

Shaw, W., Pransky, G., Patterson, W., \& Winters, T. (2005). Early disability risk factors for low back pain assessed at outpatient occupational health clinics. Spine, 30, 570-580. 
doi: 10.1097/01.brs.0000154628.37515.ef

Stillman, T., Baumeister, R., Lambert, N., Crescioni, A., DeWall, N., \& Fincham, F. (2009).

Alone and without purpose: Life loses meaning following social exclusion. Journal of Experimental Social Psychology, 45, 686-694.

http://dx.doi.org/10.1016/j.jesp.2009.03.007

Szymanski, E., \& Hershenson, D. (1998). Career Development of people with disabilities: An ecological model. In R. Parker \& E. Szymanski (Eds.), Career Choice and Development ( $3^{\text {rd }}$ ed.) (pp. 327-378). Austin, TX: Pro-ed.

Van Veldhoven, M., Meijman, T., Broersen, J., \& Fortuin, R. (2002). Handleiding VBBA (Manual QEEW). Amsterdam: SKB

Van Veldhoven, M., Taris, T., de Jonge, J., \& Broersen, S. (2005). The relationship between work characteristics and employee health and well-being: how much complexity do we really need? International Journal of Stress Management, 12, 3-28. doi: 10.1037/1072-5245.12.1.3

Waddell, G. (2006). Preventing incapacity in people with musculoskeletal disorders. British Medical Bulletin, 77, 1-15. doi: 10.1093/bmb/ldl008

Young, A. (2010). Employment maintenance and the factors that impact it after vocational rehabilitation and return to work. Disability \& Rehabilitation, 32, 1621-1632. doi:10.3109/09638281003611029

Zieger, M., Luppa, M., Meisel, H., Gunther, L., Winkler, D., Toussaint, R., ...Riedel- 
Heller, S. (2011). The impact of psychiatric comorbidity on the return to work in patients undergoing herniated disc surgery. Journal of Occupational Rehabilitation, 21, 54-65. doi: 10.1007/s10926-010-9257-1

Zimet, G., Dahlem, N., Zimet, S., \& Farley, G. (1988). The Multidimensional Scale of Perceived Social Support. Journal of Personality Assessment, 52, 30-41. doi: 10.1207/s15327752jpa5201_2

Zimet, G., Powell, S., Farley, G., Werkman, S., \& Berkoff, K. (1990). Psychometric characteristics of the Multidimensional Scale of Perceived Social Support. Journal of Personality Assessment, 55, 610-617. doi: 10.1080/00223891.1990.9674095 
Table 1

Nature of the Reported Injuries within the Sample.

\begin{tabular}{lcc}
\hline Type of Injury & $n$ & Percentage of Sample \\
\hline Upper Extremity & 29 & 29.6 \\
Lower Extremity & 20 & 20.4 \\
Musculoskeletal & 26 & 26.5 \\
Psychological & 7 & 7.1 \\
Multiple Injuries & 16 & 16.3 \\
\hline
\end{tabular}


Table 2

Relationship with Superior and Colleagues for Durable RTW and Non-durable RTW Groups

\begin{tabular}{lllll}
\hline RTW Status & \multicolumn{2}{c}{ Superior } & \multicolumn{2}{c}{ Colleagues } \\
\hline & $M$ & $S D$ & $M$ & $S D$ \\
Durable RTW & $26.35^{* *}$ & 25.75 & $28.03^{*}$ & 21.31 \\
& & & & \\
Non-durable RTW & $47.41 * *$ & 21.97 & $41.90^{*}$ & 16.82 \\
\hline
\end{tabular}

Note. $\mathrm{RTW}=$ Return to Work

${ }^{*} p<.05 ;{ }^{* *} p<.01$ 
Table 3

Multidimensional Social Support for Durable RTW, Non-durable RTW, and NRTW Groups

\begin{tabular}{lll}
\hline RTW Status $(n)$ & $M$ & $S D$ \\
\hline Durable RTW $(n=50)$ & 63.23 & 15.24 \\
Non-durable RTW $(n=26)$ & 61.75 & 17.85 \\
NRTW $(n=24)$ & 63.59 & 20.34 \\
\hline
\end{tabular}

Note. RTW = Return to Work, NRTW = No Return to Work 